\title{
ANÁLISE DOS ATRIBUTOS PARA AVALIAÇÃO DA QUALIDADE DA INFORMAÇÃO NOS AMBIENTES DE INTRANET PARA APOIO À GESTÃO DO CONHECIMENTO
}

\author{
Ana Lúcia Batista Trindade \\ analutrin@yahoo.com.br \\ Pontifícia Universidade Católica do Rio Grande do Sul - Porto Alegre, RS/Brasil \\ Mírian Oliveira \\ miriano@pucrs.br \\ Pontifícia Universidade Católica do Rio Grande do Sul - Porto Alegre, RS/Brasil \\ Grace Vieira Becker \\ grace.becker@pucrs.br \\ Pontifícia Universidade Católica do Rio Grande do Sul - Porto Alegre, RS/Brasil
}

Recebido em 25/01/2010

Aprovado em 16/05/2011

Disponibilizado em 01/12/2011

Avaliado pelo sistema double blind review

Revista Eletrônica de Administração

Editor: Luís Felipe Nascimento

ISSN 1413-2311 (versão on-line)

Editada pela Escola de Administração da Universidade Federal do Rio Grande do Sul.

Periodicidade: Quadrimestral

Sistema requerido: Adobe Acrobat Reader.

\section{RESUMO}

Esta pesquisa tem como objetivo analisar os atributos para a avaliação da qualidade da informação disponibilizada no ambiente de intranet, como suporte à gestão do conhecimento, em empresas de desenvolvimento de software. O método de pesquisa adotado foi o qualitativo, utilizando o estudo de casos múltiplos em três empresas da área de desenvolvimento de software localizadas no Brasil. Na primeira fase, através de entrevistas com especialistas, foram identificados 9 atributos (precisão, clareza, relevância, credibilidade, completeza, atualidade, tempestividade, apresentação, concisão) considerados mais relevantes para avaliação da qualidade da informação no contexto pesquisado, e 17 atributos secundários, que receberam críticas dos especialistas. $\mathrm{Na}$ segunda fase, por meio de entrevistas realizadas com colaboradores das empresas estudadas, foi possível confirmar os atributos identificados pelos especialistas, acrescentando outros que tinham recebido críticas dos mesmos. A partir da análise de conteúdo identificou-se um conjunto de 9 atributos da qualidade da informação, sugeridos como aplicáveis no ambiente de intranet como suporte à gestão do conhecimento, em empresas de desenvolvimento de software (precisão, clareza, relevância, credibilidade, completeza, atualidade, tempestividade, fonte e ordem). A avaliação da qualidade da informação da intranet foi considerada importante para aumentar a 
Ana Lúcia Batista Trindade, Mírian Oliveira \& Grace Vieira Becker

credibilidade da informação que é disponibilizada e obter algum benefício com esta informação que auxilie o processo de desenvolvimento de software.

Palavras-chave: qualidade da informação, atributos, avaliação, gestão do conhecimento, intranet.

\title{
ANALYSIS OF ATTRIBUTES FOR INFORMATION QUALITY EVALUATION IN INTRANET ENVIRONMENTS TO SUPPORT KNOWLEDGE MANAGMENT
}

\begin{abstract}
This research analyses the applicable attributes for information quality assessment in intranet environment supporting knowledge management in software development companies. It was adopted a qualitative research method using a multiple case study in three software development companies located in Brazil. In the first phase, it was identified 9 primary attributes (precision, clarity, relevancy, credibility, completeness, actuality, timing, presentation and concision), considered more relevant for information quality assessment within the research context and 17 secondary attributes that had some restrictions according to the specialists' analysis. In the second phase, it was confirmed the attributes accepted by the specialists and included other attributes that received some restrictions from the specialists. The intranet users analysis resulted in a set of 9 attributes of the information quality suggested as applicable in the Intranet environment was identified to support the knowledge management in companies of software development (precision, clarity, relevancy, credibility, completeness, actuality, timing, source and order). The information quality evaluation was considered important to improve the information credibility and to obtain benefits using this information to support the software development process. It was identified that, there is a relationship among the selected attributes. For example, it is observed that the credibility is the result of the evaluation of all attributes.
\end{abstract}

Keywords: information quality, knowledge management, intranet, evaluation.

\section{ANALICE DE LOS ATRIBUTOS PARA EVALUACIÓN DE LA CALIDAD DE LA INFORMACIÓN EN LOS AMBIENTES DE INTRANET PARA APOYO A LA GESTIÓN DEL CONOCIMIENTO}

\begin{abstract}
RESUMEN
Esta investigación tiene como objetivo analizar los atributos para la evaluación de la calidad de la información en lo ambiente de intranet, para apoyo a la gestión del conocimiento en empresas de desarrollo de software. El método de investigación adoptado fue el cualitativo utilizando el estudio de casos múltiples en tres empresas del área de desarrollo de software localizadas en Brasil. En la primera fase, por medio de entrevistas con especialistas fueron identificados 9 atributos (precisión, clareza, relevancia, credibilidad, completeza, actualidad, tempestividad, presentación, concisión), considerados más relevantes para evaluación de la calidad de la información en el contexto investigado, y 17 atributos secundarios, que
\end{abstract}


Análise dos atributos para avaliação da qualidade da informação nos ambientes de intranet para apoio à gestão do conhecimento

recibieron críticas de los especialistas. En la segunda fase, por medio de entrevistas realizadas con colaboradores de las empresas estudiadas, fue posible confirmar las condiciones identificadas por los especialistas, agregando otras que habían recibido críticas de los mismos. A partir del analice de contenido se identificó un conjunto de 9 atributos de la calidad de información sugerida como aplicables en el ambiente de intranet, como soporte a la gestión del conocimiento en empresas de desarrollo de software (precisión, clareza, relevancia, credibilidad, completeza, actualidad, tempestividad, fuente y orden). La evaluación de la calidad de la información de la intranet fue considerada importante para aumentar la credibilidad de la información que está disponible y obtener algún beneficio con esta información que auxilie el proceso de desarrollo de software.

Palabras Clave: calidad de la información, gestión del conocimiento, intranet.

\section{Introdução}

A transição da sociedade industrial para a sociedade da informação e do conhecimento é acompanhada por um conjunto de novos valores, onde os bens intangíveis são considerados recursos estratégicos e indispensáveis às organizações (Toffler, 2000). Considerando o conhecimento como recurso estratégico, deve passar a ser gerenciado como qualquer outro recurso tangível.

A gestão do conhecimento (GC) torna-se determinante para capacitar as organizações a lidarem com um ambiente que, além de complexo, modifica-se rapidamente, podendo ser um fator de diferenciação estratégica para as empresas. A gestão do conhecimento é um conjunto de processos que permite a criação, disseminação e utilização do conhecimento para atingir os objetivos da organização (TEIXEIRA FILHO, 2000). A GC auxilia na obtenção de vantagem competitiva sustentável (LEE; KIM, 2001; JASIMUDDIN, 2007).

Nonaka (1994) apresenta a conversão do conhecimento tático e explícito através da espiral do conhecimento, apresentando quatro modos de conversão: socialização (tácito para tácito), externalização (tácito para explícito), combinação (explícito para explícito) e internalização (explícito para tácito). O conhecimento tácito é obtido pelos indivíduos através de suas experiências e habilidades, enquanto o conhecimento explícito pode ser facilmente estruturado e armazenado em documentos (SHAH et al., 2007).

A tecnologia da informação (TI) é considerada um dos elementos-chave na GC, pois sustenta o conjunto de processos na transformação de conhecimento tácito em explícito e na criação de novo conhecimento. Dentre as tecnologias da informação que podem dar suporte à conversão do conhecimento, muitas organizações utilizam a intranet (MASREK; KARIM; HUSSEIN, 2008).

Uma enorme quantidade de informação pode ser compartilhada e transformada em 
Ana Lúcia Batista Trindade, Mírian Oliveira \& Grace Vieira Becker

conhecimento através da intranet. Neste ambiente, a qualidade da informação disponibilizada não pode ser considerada um fator que desestimule sua utilização, principalmente nas áreas onde a tecnologia da informação é empregada no apoio a processos e o conhecimento é o foco do negócio - este é o caso das empresas que desenvolvem software. Vários autores (STRONG; LEE; WANG, 1997; KAHN; STRONG; WANG, 2002; JENNEX; OLFMAN, 2002; LIMA; MAÇADA, 2007) apresentam atributos para avaliação da qualidade da informação. No entanto, não existe um consenso entre os autores quanto aos atributos adequados para avaliar a qualidade da informação. Além disto, a avaliação da qualidade da informação associada à GC ainda é uma lacuna nas investigações. O problema de pesquisa para o qual se buscou a resposta ficou assim formulado: Quais atributos devem ser utilizados para a avaliação da qualidade da informação disponibilizada no ambiente de intranet como apoio à GC, no contexto de empresas de desenvolvimento de software?

Nas empresas de desenvolvimento de software, nas quais os profissionais do conhecimento raramente trabalham de forma isolada, destaca-se a importância do processo de compartilhamento de conhecimento de um indivíduo ou especialista para o nível organizacional (RUS; LINDAVALL, 2002). Para as organizações de desenvolvimento de software, o conhecimento pode ser considerado como seu principal ativo porque podem alcançar melhores resultados com sua efetiva gestão.

Portanto, esta pesquisa tem como objetivo analisar atributos para avaliação da qualidade da informação disponibilizada no ambiente de intranet como apoio à GC, no contexto de empresas de desenvolvimento de software.

\section{Intranet, atributos da qualidade da informação e gestão do conhecimento}

O termo intranet é entendido como a aplicação da tecnologia de internet utilizada internamente na organização, que se conecta com a internet global (MASREK; KARIM; HUSSEIN, 2008). Dependendo da maturidade da empresa no uso da intranet, tal tecnologia será utilizada para publicar informação corporativa, como uma ferramenta de colaboração ou como uma interface para acessar outros sistemas corporativos. As empresas estão utilizando a intranet como uma ferramenta para comunicação corporativa, projetos colaborativos e para estabelecer um senso de comunidade de uma maneira gerenciável (SCOTT, 1998). Para Skok e Kalmanovitch (2005), a intranet é um facilitador dos fluxos de conhecimento dentro da organização, permitindo, também, a identificação de tendências e conexões baseadas em fatos e figuras que a mente humana não pode processar. 
Análise dos atributos para avaliação da qualidade da informação nos ambientes de intranet para apoio à gestão do conhecimento

A intranet pode ser considerada como um importante mecanismo de comunicação e integração, encorajando o compartilhamento de conhecimento entre os diversos grupos nas organizações. Sob esta ótica, a intranet faz parte da solução para problemas de gerenciamento de conhecimento (NEWELL; SCARBROUGH; SWAN, 2001). Stenmark (2002) sugeriu um modelo de suporte à GC em que a intranet é vista como um ambiente de compartilhamento de conhecimento sob as perspectivas de: a) informação - permitindo o acesso à informação estruturada e não-estruturada no formato de banco de dados e documentos; b) conhecimento utilizada para manter os usuários bem informados e conectados à informação e às pessoas na organização; e, c) comunicação - permitindo que os membros da organização interpretem coletivamente a informação disponível, suportando várias formas de canais de conversação e negociação.

Além disso, é considerada uma ferramenta estratégica para a GC. Em vez de ser avaliada como uma ferramenta em que o conhecimento é armazenado de uma forma estática, a intranet tornou-se um complexo sistema de práticas discursivas, disponibilizando textos, relatórios, fotos, números, gráficos, estatísticas e representações em geral, os quais dão significado ao mundo real e organizam os processos sociais (EDENIUS; BORGERSON, 2003).

Para garantir a efetividade da utilização da intranet como ferramenta de apoio à GC, é necessário analisar a qualidade da informação que está sendo gerenciada. O conceito de qualidade da informação utilizado neste estudo é o adotado por Conradie e Kruger (2006): qualidade em todas as características da informação, que atendam às expectativas dos usuários e dos consumidores finais. A qualidade da informação é necessária para suportar um processo efetivo de tomada de decisão (PRICE; SHANKS, 2005). Para esta pesquisa, são consideradas as decisões necessárias durante as etapas do processo de desenvolvimento de software.

Para garantir a manutenção da qualidade da informação, sugerem-se atributos que podem ser utilizados como mecanismo de avaliação da qualidade. O Quadro 1 mostra um resumo sobre os atributos de qualidade da informação encontrados na literatura pesquisada. Na coluna da esquerda, consta a relação dos atributos propostos pelos autores; nas colunas à direita, identificam-se os autores e os atributos considerados em seus trabalhos; e, na última coluna à direita, a quantidade de citações identificadas. 
Ana Lúcia Batista Trindade, Mírian Oliveira \& Grace Vieira Becker

Quadro 1 - Atributos de Qualidade da Informação pesquisados na literatura

\begin{tabular}{|c|c|c|c|c|c|c|c|c|c|c|c|c|c|c|}
\hline \multirow[b]{2}{*}{$\begin{array}{l}\text { Atributos da } \\
\text { Qualidade da } \\
\text { Informação }\end{array}$} & \multicolumn{13}{|c|}{ Autores } & \multirow[b]{2}{*}{ 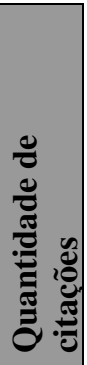 } \\
\hline & 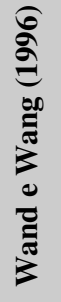 & 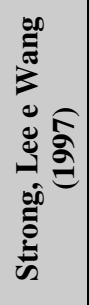 & 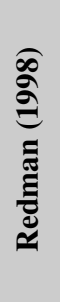 & 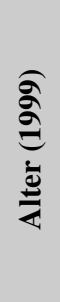 & 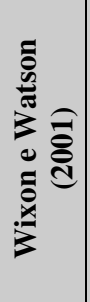 & 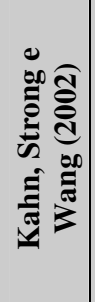 & 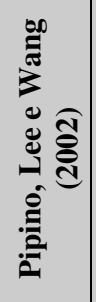 & 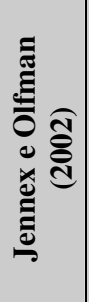 & 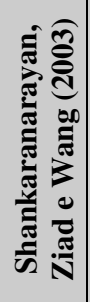 & 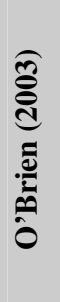 & 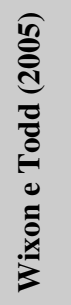 & 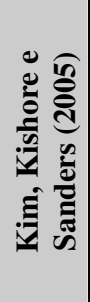 & 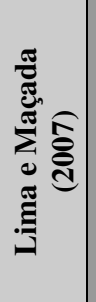 & \\
\hline Completeza & $\mathrm{X}$ & $\mathrm{X}$ & $\mathrm{X}$ & $\mathrm{X}$ & $\mathrm{X}$ & $\mathrm{X}$ & $\mathrm{X}$ & $\mathrm{X}$ & $\mathrm{X}$ & & $\mathrm{X}$ & $\mathrm{X}$ & $\mathrm{X}$ & 12 \\
\hline Acurácia & $\mathrm{X}$ & $\mathrm{X}$ & $\mathrm{X}$ & $\mathrm{X}$ & $\mathrm{X}$ & & & $\mathrm{X}$ & $\mathrm{X}$ & & $\mathrm{X}$ & $\mathrm{X}$ & & 9 \\
\hline Relevância & $\mathrm{X}$ & $\mathrm{X}$ & $\mathrm{X}$ & & & $\mathrm{X}$ & $\mathrm{X}$ & $\mathrm{X}$ & & $\mathrm{X}$ & & $\mathrm{X}$ & & 8 \\
\hline Temporalidade & $\mathrm{X}$ & $\mathrm{X}$ & $\mathrm{X}$ & $\mathrm{X}$ & & $\mathrm{X}$ & $\mathrm{X}$ & & $\mathrm{X}$ & & & & $\mathrm{X}$ & 8 \\
\hline Concisão & $\mathrm{X}$ & $\mathrm{X}$ & & & & $X$ & $X$ & & & $\mathrm{X}$ & & & & 5 \\
\hline Consistência & $\mathrm{X}$ & $\mathrm{X}$ & & & $\mathrm{X}$ & $\mathrm{X}$ & $X$ & & & & & & & 5 \\
\hline Acessibilidade & & $\mathrm{X}$ & & & & $\mathrm{X}$ & $\mathrm{X}$ & & & & & $\mathrm{X}$ & $\mathrm{X}$ & 5 \\
\hline Atualidade & $\mathrm{X}$ & & & & & & & $\mathrm{X}$ & & & $\mathrm{X}$ & $\mathrm{X}$ & & 4 \\
\hline Credibilidade & & $X$ & & & & $X$ & $\mathrm{X}$ & & & & & & $\mathrm{X}$ & 4 \\
\hline Inteligibilidade & $\mathrm{X}$ & $\mathrm{X}$ & & & & $\mathrm{X}$ & & & & & & & $\mathrm{X}$ & 4 \\
\hline Interpretabilidade & $\mathrm{X}$ & $\mathrm{X}$ & & & & $\mathrm{X}$ & & & & & & & $\mathrm{X}$ & 4 \\
\hline Precisão & $\mathrm{X}$ & & & $\mathrm{X}$ & & & & & & $\mathrm{X}$ & & & & 3 \\
\hline Quantidade & & $\mathrm{X}$ & & & & $\mathrm{X}$ & $\mathrm{X}$ & & & & & & & 3 \\
\hline Objetividade & & $\mathrm{X}$ & & & & $\mathrm{X}$ & & & & & & & $\mathrm{X}$ & 3 \\
\hline Reputação & & $\mathrm{X}$ & & & & $\mathrm{X}$ & & & & & & & $\mathrm{X}$ & 3 \\
\hline Clareza & $\mathrm{X}$ & & & & & & & & & $\mathrm{X}$ & & & & 2 \\
\hline Detalhe & $\mathrm{X}$ & & & & & & & & & $\mathrm{X}$ & & & & 2 \\
\hline Facilidade de uso & & & & & & $\mathrm{X}$ & $\mathrm{X}$ & & & & & & & 2 \\
\hline Formato & $\mathrm{X}$ & & & & & & & & & & $\mathrm{X}$ & & & 2 \\
\hline Livre de erro & & & & & & $\mathrm{X}$ & $\mathrm{X}$ & & & & & & & 2 \\
\hline Tempestividade & & & & & & & & $\mathrm{X}$ & & $\mathrm{X}$ & & & & 2 \\
\hline Segurança & & $\mathrm{X}$ & & & & $\mathrm{X}$ & & & & & & & & 2 \\
\hline Valor & & $\mathrm{X}$ & & & & $\mathrm{X}$ & & & & & & & & 2 \\
\hline Aceitação & & & & & & & & & & $\mathrm{X}$ & & & & 1 \\
\hline Amplitude & & & & & & & & & & $\mathrm{X}$ & & & & 1 \\
\hline Apresentação & & & & & & & & & & $\mathrm{X}$ & & & & 1 \\
\hline Comparabilidade & $\mathrm{X}$ & & & & & & & & & & & & & 1 \\
\hline Compreensão & & & & & $\mathrm{X}$ & & & & & & & & & 1 \\
\hline Confiabilidade & $\mathrm{X}$ & & & & & & & & & & & & & 1 \\
\hline Conteúdo & $\mathrm{X}$ & & & & & & & & & & & & & 1 \\
\hline Desempenho & & & & & & & & & & $\mathrm{X}$ & & & & 1 \\
\hline Disponibilidade & & & & & & & & & & & & $\mathrm{X}$ & & 1 \\
\hline Eficiência & $\mathrm{X}$ & & & & & & & & & & & & & 1 \\
\hline Empacotamento & & & & & & & & & & & & $\mathrm{X}$ & & 1 \\
\hline Escopo & $\mathrm{X}$ & & & & & & & & & & & & & 1 \\
\hline Flexibilidade & $\mathrm{X}$ & & & & & & & & & & & & & 1 \\
\hline Fonte & & & & $\mathrm{X}$ & & & & & & & & & & 1 \\
\hline Freqüência & & & & & & & & & & $\mathrm{X}$ & & & & 1 \\
\hline Histórico & & & & & & & & & & & & $\mathrm{X}$ & & 1 \\
\hline Idade & & & & $\mathrm{X}$ & & & & & & & & & & 1 \\
\hline Importância & $\mathrm{X}$ & & & & & & & & & & & & & 1 \\
\hline Informatividade & $\mathrm{X}$ & & & & & & & & & & & & & 1 \\
\hline Integridade & & & & & & & & & & $\mathrm{X}$ & & & & 1 \\
\hline Interface & & & & & & & & & & & & $\mathrm{X}$ & & 1 \\
\hline Livre de viés & $\mathrm{X}$ & & & & & & & & & & & & & 1 \\
\hline Mídia & & & & & & & & & & $\mathrm{X}$ & & & & 1 \\
\hline Ordem & & & & & & & & & & $\mathrm{X}$ & & & & $\mathbf{1}$ \\
\hline Período & & & & & & & & & & $\mathrm{X}$ & & & & 1 \\
\hline Suficiência & $\mathrm{X}$ & & & & & & & & & & & & & 1 \\
\hline Usabilidade & $\mathrm{X}$ & & & & & & & & & & & & & 1 \\
\hline Utilidade & $\mathrm{X}$ & & & & & & & & & & & & & 1 \\
\hline
\end{tabular}


Análise dos atributos para avaliação da qualidade da informação nos ambientes de intranet para apoio à gestão do conhecimento

No Quadro 2, são apresentadas as definições dos atributos de qualidade da informação dos autores pesquisados, visando um melhor entendimento do significado de cada atributo.

Quadro 2 - Definição dos atributos da Qualidade da Informação com base nos autores pesquisados

\begin{tabular}{|c|c|}
\hline Atributos & Descrição \\
\hline Aceitação & A informação deve ser atualizada quando for fornecida. \\
\hline Acessibilidade & $\begin{array}{l}\text { A facilidade e a eficiência com que o usuário pode navegar na aplicação para } \\
\text { acessar a informação desejada. }\end{array}$ \\
\hline Acurácia & $\begin{array}{l}\text { A percepção de que a informação está correta. A informação do sistema representa } \\
\text { a situação do mundo real. Representação do que se supõe e do que se pretende. }\end{array}$ \\
\hline Amplitude & $\begin{array}{l}\text { A informação pode ter um alcance amplo ou estreito, ou um foco interno ou } \\
\text { externo. }\end{array}$ \\
\hline Apresentação & $\begin{array}{l}\text { A informação pode ser apresentada em forma narrativa, numérica, gráfica ou } \\
\text { outras. }\end{array}$ \\
\hline Atualidade & $\begin{array}{l}\text { O quanto que a informação está atualizada. Passa a percepção de idade da } \\
\text { informação, ou seja, o tempo decorrido desde a última atualização. }\end{array}$ \\
\hline Clareza & A informação deve ser fornecida de forma que seja de fácil compreensão. \\
\hline Completeza & $\begin{array}{l}\text { O sistema provê toda a informação necessária para a execução da atividade. } \\
\text { Quando todos os valores necessários estão incluídos. }\end{array}$ \\
\hline Concisão & $\begin{array}{l}\text { A informação é apresentada de forma compacta. Apenas a informação que for } \\
\text { necessária deve ser fornecida. }\end{array}$ \\
\hline Confiabilidade & $\begin{array}{l}\text { Probabilidade de prevenir erros ou falhas. Está relacionada com o quanto a } \\
\text { informação está correta. }\end{array}$ \\
\hline Consistência & A informação é apresentada no mesmo formato. \\
\hline Credibilidade & A informação é considerada verdadeira e confiável. \\
\hline Desempenho & $\begin{array}{l}\text { A informação pode revelar desempenho pela mensuração das atividades concluídas, } \\
\text { progresso realizado ou recursos acumulados. }\end{array}$ \\
\hline Detalhe & A informação pode ser fornecida em forma detalhada ou resumida. \\
\hline Disponibilidade & $\begin{array}{l}\text { Refere-se à flexibilidade e compreensão das características da aplicação } \\
\text { disponibilizadas para os usuários para especificar e controlar a relação temporal } \\
\text { entre os vários componentes hipermídia para que seja disponibilizada uma } \\
\text { informação de hipermídia integrada. }\end{array}$ \\
\hline Empacotamento & $\begin{array}{l}\text { Refere-se à variedade de informações com que os vários tipos de mídias são } \\
\text { empacotados dentro de uma interface web para apresentação para ao usuário final. }\end{array}$ \\
\hline Facilidade de uso & A informação é fácil de ser manipulada e aplica-se a diferentes atividades. \\
\hline Fonte & Quem produziu a informação. \\
\hline Formato & Como a informação é apresentada. \\
\hline Freqüência & A informação deve ser fornecida tantas vezes quantas forem necessárias. \\
\hline Histórico & $\begin{array}{l}\text { Refere-se à flexibilidade e compreensão das características da aplicação } \\
\text { disponibilizadas para os usuários para especificar e manter um histórico das ações } \\
\text { dos usuários e do estado da aplicação. }\end{array}$ \\
\hline Idade & Tempo decorrido desde a sua produção. \\
\hline Integridade & Toda a informação necessária deve ser fornecida. \\
\hline Inteligibilidade & A informação é facilmente entendida. \\
\hline Interface & $\begin{array}{l}\text { Consistência no arranjo estrutural e no estilo do conteúdo da informação e } \\
\text { hiperlinks dentro da aplicação. A interface deve permitir que o usuário conheça o } \\
\text { conteúdo da informação disponibilizada nas páginas web. }\end{array}$ \\
\hline Interpretabilidade & $\begin{array}{l}\text { A informação está disponível em linguagem e símbolos apropriados, e as definições } \\
\text { são claras. }\end{array}$ \\
\hline Livre de erro & A informação está correta e confiável. \\
\hline Mídia & $\begin{array}{l}\text { A informação pode ser fornecida na forma de documentos em papel impresso, } \\
\text { monitores de vídeo ou outras mídias. }\end{array}$ \\
\hline
\end{tabular}

Continuação

Objetividade $\quad$ A informação não é tendenciosa e é imparcial. 
Ana Lúcia Batista Trindade, Mírian Oliveira \& Grace Vieira Becker

\begin{tabular}{|c|l|}
\hline Ordem & A informação pode ser organizada em uma sequiência pré-determinada. \\
\hline Período & A informação pode ser fornecida sobre períodos passados, presentes ou futuros. \\
\hline Precisão & $\begin{array}{l}\text { A informação deve estar isenta de erros. Nível de detalhe suficiente para o uso que } \\
\text { se destina. }\end{array}$ \\
\hline Tempestividade & A informação deve ser fornecida quando for necessária. \\
\hline Quantidade & $\begin{array}{l}\text { O quanto o volume de informação é apropriado para a atividade que está sendo } \\
\text { executada. }\end{array}$ \\
\hline Relevância & $\begin{array}{l}\text { A informação deve estar relacionada com o interesse e as necessidades de } \\
\text { informação do usuário. }\end{array}$ \\
\hline Reputação & A informação é considerada verdadeira com relação à sua fonte ou conteúdo. \\
\hline Segurança & $\begin{array}{l}\text { O acesso à informação é mantido restrito apropriadamente para gantir a sua } \\
\text { segurança. }\end{array}$ \\
\hline Temporalidade & $\begin{array}{l}\text { A informação está suficientemente atualizada. A idade da informação é adequada } \\
\text { para a necessidade do usuário. }\end{array}$ \\
\hline Valor & A informação provê benefícios e vantagens com o seu uso. \\
\hline
\end{tabular}

Fonte: autores pesquisados

Conforme observado, não existe um consenso entre os autores na escolha dos atributos de qualidade adequados para avaliar a qualidade da informação. Pode-se constatar o aspecto multidimensional proposto pelos autores na identificação dos atributos da qualidade da informação. Os atributos sugeridos no trabalho de Strong, Lee e Wang (1997) são utilizados pelos demais autores nas suas propostas. A metodologia proposta por Kahn, Strong e Wang (2002) é uma evolução do seu primeiro trabalho, acrescentando o atributo de facilidade de uso. O modelo proposto por Kim, Kishore e Sanders (2005) utiliza alguns dos atributos de Strong, Lee e Wang (1997), considerando uma visão diferenciada nas dimensões (conteúdo, forma e tempo) e sugerindo novos atributos que enfocam problemas de usabilidade (disponibilidade, empacotamento, histórico e interface). Jennex e Olfman (2002) sugerem alguns atributos que podem ser aplicados em sistemas que controlam a memória organizacional e o conhecimento nas organizações, sendo o único trabalho com foco em GC. Os atributos escolhidos por Jennex e Olfman (2002) estão contidos no conjunto proposto por Strong, Lee e Wang (1997), acrescentando apenas a tempestividade da informação, que está relacionada com o aspecto temporal da informação. Shankaranarayan, Ziad e Wang (2003) consideram apenas três atributos, os quais estão presentes na proposta de Strong, Lee e Wang (1997). Redman (1998) considera quatro atributos também presentes na proposta de Strong, Lee e Wang (1997). Lima e Maçada (2007) também utilizam os atributos propostos por Strong, Lee e Wang (1997); o resultado do trabalho, contudo, propõe um instrumento com 4 dimensões consideradas relevantes para o setor bancário, no qual a pesquisa foi aplicada.

É importante considerar que o objetivo dos estudos dos autores citados no Quadro 1, ao apresentar os atributos de qualidade da informação, foi diferente, o que pode estar relacionado com a diversidade de escolha dos atributos. Os autores que salientam a 
Análise dos atributos para avaliação da qualidade da informação nos ambientes de intranet para apoio à gestão do conhecimento

importância da avaliação da qualidade da informação em termos quantitativos são Wand e Wang (1996), Kahn, Strong e Wang (2002), Pipino, Lee e Wang (2002), Shankaranarayan, Ziad e Wang (2003) e Lima e Maçada (2007), os quais sugerem metodologias para a avaliação da qualidade da informação nos sistemas de informações. Kahn, Strong e Wang (2002), Pipino, Lee e Wang (2002) sugerem que, com a aplicação da medição de avaliação da qualidade da informação nas organizações, pode ser estabelecido um benchmark de qualidade da informação.

Outra abordagem para análise dos atributos de qualidade da informação apresentada trata do tipo de sistema de informações em relação aos quais foram aplicados. Wixon e Watson (2001) e Wixon e Todd (2005) aplicam o conjunto de atributos para avaliação da qualidade da informação dos sistemas de Data Warehousing. Jennex e Olfman (2002) sugerem atributos para avaliar os sistemas que suportam a memória e o conhecimento organizacional. Já Shankaranarayan, Ziad e Wang (2003) e Kim, Kishore e Sanders (2005) propõem o conjunto de atributos para avaliar os sistemas de e-business - Kim, Kishore e Sanders (2005) abordam os sistemas de e-business construídos em tecnologia de internet, web e hipermídia. Lima e Maçada (2007) desenvolvem um modelo aplicado para avaliar a qualidade da informação de sistemas bancários.

Apesar de não existir um consenso entre os autores na utilização dos atributos para avaliar a qualidade da informação, alguns destes atributos são citados por diversos autores, conforme pode ser observado na coluna Quantidade de Citações no Quadro 1. Dos atributos apresentados, os mais citados pelos autores foram completeza, acurácia, relevância, temporalidade, concisão, consistência e acessibilidade.

\section{Método de pesquisa}

O método de pesquisa escolhido para este trabalho foi o qualitativo, permitindo uma melhor visão e compreensão do contexto do problema (MALHOTRA, 2001). Justifica-se o uso de uma pesquisa de caráter qualitativo em casos que estejam envolvidos no seu contexto real, visando obter elementos relevantes para explicar fenômenos sociais naturais (HOPPEN; LAPONT; MOREAU, 1997).

O método de estudo de caso múltiplo foi o escolhido nesta pesquisa porque investiga um fenômeno contemporâneo no seu contexto real. Para aumentar a confiabilidade de um 
Ana Lúcia Batista Trindade, Mírian Oliveira \& Grace Vieira Becker

estudo de caso, Yin (2005) sugere a utilização de um protocolo, o que foi adotado nesta pesquisa. Com relação à natureza deste estudo, a pesquisa é exploratória, pois tem como objetivo proporcionar maior familiaridade com o problema, aprimorando idéias, descobertas ou intuições (GIL, 1991).

Primeiramente, desenvolveu-se uma pesquisa bibliográfica para melhor entender o problema da pesquisa e obter material teórico para fundamentação do estudo. A revisão da literatura foi realizada durante todo o desenvolvimento da pesquisa.

Os casos desta pesquisa foram selecionados em função de se configurarem como fontes de conhecimento e aprendizado em relação ao fenômeno estudado. $\mathrm{O}$ estudo foi feito em três empresas da área de tecnologia da informação com foco em desenvolvimento de software - por questões de sigilo, as empresas foram denominadas ao longo deste trabalho como Empresa A, Empresa B e Empresa X. A Empresa X, que se localiza no Estado do Rio Grande do Sul, possui área de desenvolvimento de software com uma estrutura que conta com aproximadamente 500 colaboradores. Para a Empresa A, foi considerado o seu escritório no Rio de Janeiro - esta empresa presta serviços na área de Tecnologia da Informação para todo o Brasil, atuando nos setores de Finanças, Indústria e Serviços, Telecomunicações, Energia e Governo, contando com aproximadamente 1700 colaboradores. A Empresa B, um instituto privado que se localiza no Estado de Pernambuco, cria produtos, processos e serviços na área de Tecnologia da Informação e Comunicação, contando em sua estrutura com aproximadamente 640 colaboradores. Para este estudo de caso múltiplo, optou-se por realizar em uma das empresas, aqui denominada de Empresa X, um estudo de caso piloto - estudo preliminar utilizado para aprimorar os planos de coleta de dados e os procedimentos a serem seguidos no projeto de pesquisa.

A unidade de análise desta pesquisa é a área em que são desenvolvidos projetos de software. As empresas selecionadas apresentam as características adequadas para a realização da pesquisa - dentre as principais, a aplicação de práticas de gestão de conhecimento e a utilização de intranet como sistema de gestão de conhecimento no apoio ao processo de desenvolvimento de software.

Os dados foram coletados em duas fases. Na fase 1 foram realizadas entrevistas com 5 especialistas na área de gestão do conhecimento e qualidade da informação, com o objetivo de confirmar ou complementar os atributos para avaliar a qualidade da informação identificados na literatura. Na fase 2 foram entrevistados 16 usuários das intranets, os quais atuam na área 
Análise dos atributos para avaliação da qualidade da informação nos ambientes de intranet para apoio à gestão do conhecimento

de desenvolvimento de software das empresas estudadas, com o intuito de analisar os atributos sob a perspectiva dos mesmos.

$\mathrm{Na}$ fase 1 de coleta de dados, o critério para escolha dos entrevistados foi a experiência em gestão de conhecimento, qualidade da informação ou sistemas de informação. Os entrevistados são chamados ao longo deste trabalho de especialista 1 (E1), especialista 2 (E2), especialista 3 (E3), especialista 4 (E4) e especialista 5 (E5). O especialista 1 é doutor em Sistemas da Informação na área de Administração, professor atuando na área de pesquisa de Ciência da Computação com ênfase em Sistemas de Informação. O especialista 2 é doutor em Sistemas da Informação, e atua como consultor em empresas nos Estados Unidos e Brasil na área de Gestão de Conhecimento. O especialista 3 é doutor em Administração, e professor atuando na área de Tecnologia da Informação e Qualidade da Informação. O especialista 4 é doutor em Engenharia de Produção, atua como professor de vários cursos de MBA e pósgraduação e é consultor em empresas no Brasil, Estados Unidos, Canadá, França e Japão, apoiando os programas de Gestão do Conhecimento e Portais Corporativos. O especialista 5 é mestre em Administração e Negócios, atua como gerente de projetos na área de desenvolvimento de software e possui artigos publicados na área de Gestão do Conhecimento.

O roteiro de entrevista foi elaborado com base no referencial teórico encontrado, relacionando os atributos para avaliar a qualidade da informação na intranet como apoio ao processo de gestão de conhecimento. O roteiro da entrevista semi-estruturada foi elaborado e validado por dois professores que atuam em pós-graduação na área de administração. $\mathrm{O}$ roteiro foi revisado e modificado de acordo com as sugestões destes professores.

Durante a entrevista, os atributos identificados na literatura com suas respectivas definições foram apresentados aos entrevistados, os quais também foram solicitados a complementar a lista de atributos. As entrevistas com os especialistas foram realizadas pessoalmente, com duração aproximada de uma hora. Somente com o especialista 4 a entrevista foi realizada por telefone, em função da distância geográfica observada naquele período.

Na segunda fase de coleta dos dados, o critério para definição dos entrevistados foi focado no papel que eles desempenham dentro da área de desenvolvimento de software e no seu envolvimento com práticas de GC nas empresas.

O roteiro de entrevista foi elaborado com base no referencial teórico encontrado e na análise da fase 1 . O roteiro da entrevista semi-estruturada foi novamente validado por dois 
Ana Lúcia Batista Trindade, Mírian Oliveira \& Grace Vieira Becker

professores que atuam em pós-graduação na área de administração. O roteiro foi revisado e modificado de acordo com as sugestões destes professores. Durante as entrevistas, os atributos identificados na literatura com suas respectivas definições foram apresentados aos entrevistados, aos quais também foi solicitado complementar a lista de atributos.

Na Empresa X, as entrevistas foram realizadas pessoalmente com seis funcionários e cada entrevista teve a duração de aproximadamente 50 minutos. Na Empresa A as entrevistas foram conduzidas por telefone com quatro colaboradores, tendo cada entrevista a duração de aproximadamente 50 minutos. E com a Empresa B as 6 entrevistas foram realizadas por telefone, com duração de aproximadamente 50 minutos cada uma. As entrevistas foram gravadas e transcritas, sendo o conteúdo armazenado no banco de dados utilizado para a pesquisa.

Além das entrevistas, foram analisados documentos sobre as intranets das empresas. Como não foi possível acessar as intranets das mesmas, foram disponibilizados pelas empresas documentos com exemplos de páginas utilizadas pelos usuários da área de desenvolvimento de software. Desta forma, visualizaram-se as informações que estão disponibilizadas para as equipes que atuam no desenvolvimento de software. Segundo Yin (2005), as informações documentais são relevantes a todos os tipos de estudo de caso.

Os instrumentos de pesquisa foram aplicados primeiramente no caso piloto, que neste estudo é a Empresa X, assim possibilitando assegurar que, com os dados coletados, os objetivos propostos da pesquisa fossem atingidos.

Após cada fase de coleta de dados, fase 1 com especialistas e fase 2 com usuários da intranet, realizadas através de entrevistas e análise do material sobre as intranets, foi iniciado o processo de análise dos dados obtidos. A técnica de análise de dados utilizada nas duas fases (fase 1 com especialistas e fase 2 com usuários da intranet) para investigar o resultado das entrevistas foi a análise de conteúdo. Para Bardin (1977), a análise de conteúdo é um conjunto de técnicas de análise de comunicações, que utilizam procedimentos sistemáticos e objetivos de descrição de conteúdo de mensagem.

A análise temática foi utilizada para análise de conteúdo, a qual considera a contagem de um ou vários temas ou itens de significação (BARDIN, 1977). A autora sugere a categorização para classificação dos elementos constitutivos do conjunto, definindo como categorias. A análise de conteúdo realizada utilizou a categorização do conteúdo, tendo como categorias pré-definidas as dimensões e seus elementos obtidos na pesquisa bibliográfica, e 
Análise dos atributos para avaliação da qualidade da informação nos ambientes de intranet para apoio à gestão do conhecimento

também as categorias inferidas, ou seja, aquelas identificadas a partir da leitura das respostas. A análise dos dados dos documentos coletados também foi realizada utilizando a análise de conteúdo, enquanto para interpretação das informações contidas nos documentos foi utilizada a categorização.

A análise de conteúdo foi repetida para cada um dos casos estudados. Ao final, depois de realizada a análise de cada uma das empresas, os resultados obtidos permitiram uma análise comparativa dos casos.

\section{Análise dos casos}

A análise dos dados obtidos através das entrevistas foi realizada segundo as duas fases de coleta de dados: na primeira, foi considerada a visão dos especialistas em GC e qualidade da informação quanto aos atributos para avaliação da qualidade da informação nas intranets no contexto de desenvolvimento de software; na segunda fase, foi realizada a análise dos atributos da qualidade da informação sob a ótica dos usuários de intranet das empresas estudadas.

\subsection{Fase 1: atributos da qualidade da informação na visão dos especialistas}

Uma observação apontada pelos especialistas refere-se à quantidade de atributos apresentada. Eles sugeriram que, para a avaliação da qualidade da informação das intranets, a quantidade de atributos fosse diminuída. O especialista 1 sugeriu "não ter mais que 5, usar a regra de 5 mais ou menos 2". O especialista 2 colocou que "talvez possa ter mais que 5, mas não mais que 10". O Quadro 3 apresenta os atributos que tiveram a aceitação de três ou mais entrevistados e as principais observações apontadas por estes . Também foram agrupados os atributos com sobreposição em suas definições, sendo sugerida pelos especialistas a utilização de um deles, desde que as definições contemplem o mesmo aspecto da informação que avalia. 
Ana Lúcia Batista Trindade, Mírian Oliveira \& Grace Vieira Becker

Quadro 3 - Atributos da Qualidade da Informação aceitos pelos especialistas

\begin{tabular}{|c|c|c|}
\hline Atributos & Aceitação dos especialistas & Observações \\
\hline Acurácia & \multirow{2}{*}{$\begin{array}{l}\text { É um atributo importante, central neste } \\
\text { processo. É necessário ter a informação } \\
\text { correta. } \\
\text { Aceitação: E1, E2, E3, E4 e E5 }\end{array}$} & \multirow{2}{*}{$\begin{array}{l}\text { Acurácia e Precisão têm definições } \\
\text { semelhantes. Foi sugerido considerar } \\
\text { precisão que proporciona um entendimento } \\
\text { melhor para a utilização em questionários. }\end{array}$} \\
\hline Precisão & & \\
\hline Apresentação & \multirow[b]{2}{*}{$\begin{array}{l}\text { Pode ser um atributo importante. A forma de } \\
\text { apresentação é importante dependendo do } \\
\text { contexto. Pode ter um padrão de } \\
\text { apresentação, mas em formas variáveis. } \\
\text { Aceitação: E1, E3, E4 e E5 }\end{array}$} & \multirow{2}{*}{$\begin{array}{l}\text { Apresentação e Formato são semelhantes. } \\
\text { A intranet não é uma ferramenta que vai ser } \\
\text { utilizada o tempo todo, então a questão de } \\
\text { formato não é relevante. }\end{array}$} \\
\hline Formato & & \\
\hline Atualidade & $\begin{array}{l}\text { É importante ter a informação atualizada. A } \\
\text { atualidade da informação faz com que as } \\
\text { pessoas tenham mais confiabilidade na } \\
\text { informação. } \\
\text { Aceitação: E1, E2, E3, E4 e E5 }\end{array}$ & $\begin{array}{l}\text { A atualidade tem relação com } \\
\text { confiabilidade. }\end{array}$ \\
\hline Clareza & $\begin{array}{l}\text { É um atributo importante para que as } \\
\text { pessoas possam melhor entender e utilizar a } \\
\text { informação. } \\
\text { Aceitação: E1, E3, E4 e E5 }\end{array}$ & \\
\hline Completeza & $\begin{array}{l}\text { É um atributo importante. Quanto mais } \\
\text { completa for, melhor. Faz com que todo o } \\
\text { conteúdo seja apresentado. } \\
\text { Aceitação: E1, E3 e E5 }\end{array}$ & $\begin{array}{l}\text { Quanto mais completa, melhor; porem, é } \\
\text { muito difícil ter uma informação completa. } \\
\text { É difícil de medir e saber aquilo que não } \\
\text { tem. }\end{array}$ \\
\hline Concisão & $\begin{array}{l}\text { Pode ser um atributo bom. Informação } \\
\text { compacta ou de forma reduzida pode ajudar. } \\
\text { Aceitação: E1, E3 e E4 }\end{array}$ & $\begin{array}{l}\text { É um atributo que está relacionado com } \\
\text { clareza, porque quanto mais exemplos, } \\
\text { mais detalhes, mais claro poderia ficar. }\end{array}$ \\
\hline Confiabilidade & \multirow{2}{*}{$\begin{array}{l}\text { É um atributo importante porque é } \\
\text { necessário que haja confiança na informação } \\
\text { que está sendo acessada. } \\
\text { Aceitação: E1, E2, E3, E4 e E5 }\end{array}$} & \multirow{2}{*}{$\begin{array}{l}\text { Confiabilidade e Credibilidade estão } \\
\text { associadas. Foi sugerido utilizar o termo } \\
\text { credibilidade. } \\
\text { A credibilidade se relaciona com o atributo } \\
\text { acurácia. }\end{array}$} \\
\hline Credibilidade & & \\
\hline Tempestividade & $\begin{array}{l}\text { É importante ter a informação disponível } \\
\text { para ser acessada no momento que as } \\
\text { pessoas precisam. É a informação disponível } \\
\text { no momento certo. } \\
\text { Aceitação: E1, E2, E3, E4 e E5 }\end{array}$ & \\
\hline Relevância & \multirow[b]{2}{*}{$\begin{array}{l}\text { Pode ser um atributo importante. A } \\
\text { informação deve ser relevante dentro de um } \\
\text { contexto. A informação tem que ter um valor } \\
\text { adicionado. Tem que ter valor para a tomada } \\
\text { de decisão. } \\
\text { Aceitação: E1, E2, E4 e E5 }\end{array}$} & \multirow{2}{*}{$\begin{array}{l}\text { Relevância e Valor estão associados. } \\
\text { A relevância depende do contexto, mas não } \\
\text { é fácil de determinar. }\end{array}$} \\
\hline Valor & & \\
\hline
\end{tabular}

Fonte: dados da pesquisa

Os atributos da qualidade da informação que receberam críticas de três ou mais especialistas estão apresentados no Quadro 4, juntamente com a observação dos mesmos. 
Análise dos atributos para avaliação da qualidade da informação nos ambientes de intranet para apoio à gestão do conhecimento

Quadro 4 - Atributos da Qualidade da Informação que receberam críticas dos especialistas

\begin{tabular}{|c|c|}
\hline Atributos & Observações \\
\hline Aceitação & $\begin{array}{l}\text { A definição está confusa. Atualização ou dados correntes é importante, } \\
\text { mas não com este nome. O atributo atualidade contempla o que é } \\
\text { proposto na definição deste atributo. (E1, E2, E3, E5) }\end{array}$ \\
\hline Acessibilidade & No caso de intranet, acessibilidade é uma obrigação. (E2, E3, E4) \\
\hline Amplitude & $\begin{array}{l}\text { Este atributo não foi considerado importante para o contexto. Não vale a } \\
\text { pena o esforço de criar uma intranet que tenha tudo. (E1, E2, E3, E4, E5) }\end{array}$ \\
\hline Consistência & $\begin{array}{l}\text { Este atributo está contemplado na definição de apresentação ou } \\
\text { formato. (E1, E2, E3, E5) }\end{array}$ \\
\hline Desempenho & $\begin{array}{l}\text { Este atributo não foi considerado importante para este contexto. É um } \\
\text { atributo da ferramenta que contém a informação e não da informação. } \\
(\mathrm{E} 1, \mathrm{E} 2, \mathrm{E} 3, \mathrm{E} 4, \mathrm{E} 5)\end{array}$ \\
\hline Detalhe & $\begin{array}{l}\text { Este atributo pode ser contemplado pelos atributos concisão, clareza e } \\
\text { completeza. (E1, E2, E3, E4, E5) }\end{array}$ \\
\hline Disponibilidade & É um atributo da ferramenta e não da informação. (E1, E2, E3, E5) \\
\hline Empacotamento & $\begin{array}{l}\text { Este atributo não influencia no contexto de desenvolvimento de software. } \\
\text { Tem a ver com formato e clareza. (E1, E2, E3, E4, E5) }\end{array}$ \\
\hline Facilidade de uso & $\begin{array}{l}\text { No contexto de desenvolvimento pode ser um problema ter informação } \\
\text { que se aplica a diferentes atividades. (E1, E2, E4, E5) }\end{array}$ \\
\hline Fonte & $\begin{array}{l}\text { Este atributo não foi considerado importante. Pode ser contemplado pela } \\
\text { credibilidade. (E1, E2, E3) }\end{array}$ \\
\hline Freqüência & $\begin{array}{l}\text { Este atributo não foi considerado muito relevante. Pode ser contemplado } \\
\text { pelo atributo tempestividade. (E1, E2, E3, E5) }\end{array}$ \\
\hline Histórico & $\begin{array}{l}\text { Este atributo não foi considerado relevante. Pode ser contemplado pelo } \\
\text { atributo atualidade, se for mantido o histórico das atualizações. (E1, E2, } \\
\text { E5) }\end{array}$ \\
\hline Idade & $\begin{array}{l}\text { Este atributo pode ser contemplado pelo atributo atualidade. A idade está } \\
\text { associada a ultima atualização. (E1, E2, E3, E4, E5) }\end{array}$ \\
\hline Integridade & $\begin{array}{l}\text { Este atributo se sobrepõe com o atributo completeza. (E1, E2, E3, E4, } \\
\text { E5) }\end{array}$ \\
\hline Inteligibilidade & $\begin{array}{l}\text { Este atributo pode ser contemplado pelo atributo clareza. (E1, E2, E3, } \\
\text { E5) }\end{array}$ \\
\hline Interface & $\begin{array}{l}\text { Este atributo está relacionado com formato e apresentação. (E1, E2, E3, } \\
\text { E5) }\end{array}$ \\
\hline Interpretabilidade & $\begin{array}{l}\text { Este atributo se sobrepõe com as definições de clareza, apresentação e } \\
\text { formato. (E1, E2, E3, E5) }\end{array}$ \\
\hline Livre de erro & $\begin{array}{l}\text { Este atributo é contemplado pelos atributos acurácia e clareza. (E1, E2, } \\
\text { E3, E4, E5) }\end{array}$ \\
\hline Mídia & $\begin{array}{l}\text { Este atributo não foi considerado relevante. A mídia na vai influenciar a } \\
\text { qualidade na tomada de decisão. (E1, E2, E3, E5) }\end{array}$ \\
\hline Objetividade & $\begin{array}{l}\text { Este atributo é muito difícil de medir. Não existe imparcialidade na } \\
\text { informação. (E1, E2, E3, E4, E5) }\end{array}$ \\
\hline Ordem & $\begin{array}{l}\text { Não é um atributo da informação, mas da maneira como ela está } \\
\text { classificada dentro da ferramenta. (E1, E2, E5) }\end{array}$ \\
\hline Período & $\begin{array}{l}\text { Este atributo está relacionado com o atributo atualidade. (E1, E2, E3, } \\
\text { E4, E5) }\end{array}$ \\
\hline Quantidade & $\begin{array}{l}\text { Este atributo está relacionado com o atributo completeza. (E1, E2, E3, } \\
\text { E4, E5) }\end{array}$ \\
\hline Reputação & $\begin{array}{l}\text { A informação não tem reputação. O meio que produz ou transmite a } \\
\text { informação é que faz sentido associar a reputação. Este atributo pode ter } \\
\text { relação com credibilidade. (E1, E2, E3, E4, E5) }\end{array}$ \\
\hline Segurança & É um atributo difícil de medir. (E1, E2, E4) \\
\hline Temporalidade & $\begin{array}{l}\text { Este atributo é contemplado pelo atributo atualidade. (E1, E2, E3, E4, } \\
\text { E5) }\end{array}$ \\
\hline
\end{tabular}

Fonte: dados da pesquisa 
Ana Lúcia Batista Trindade, Mírian Oliveira \& Grace Vieira Becker

Apesar de estes atributos apresentarem restrições na opinião dos especialistas, na seqüência desta fase da pesquisa foram mantidos no instrumento de coleta de dados, sendo chamados de secundários. Desta forma, é possível analisar se a percepção dos especialistas é a mesma dos usuários de intranet das empresas estudadas.

\subsection{Fase 2: atributos da qualidade da informação na visão dos usuários}

Os entrevistados concordam com a importância da GC nas organizações como uma forma de manter o conhecimento das pessoas dentro da empresa; para tanto, utilizam processos e ferramentas com a finalidade de garantir que o conhecimento não esteja somente na mente das pessoas, mas sim seja disponibilizado em benefício da organização. O Quadro 5 mostra como as empresas X, A e B utilizam a intranet como ambiente de GC.

Quadro 5 - Comparação da utilização da intranet como apoio à GC nas Empresas X, A e B

\begin{tabular}{|l|l|l|}
\hline \multicolumn{3}{|c|}{ Utilização da Intranet na GC } \\
\hline \multicolumn{1}{|c|}{ Empresa X } & \multicolumn{1}{|c|}{ Empresa A } & \multicolumn{1}{c|}{ Empresa B } \\
\hline - Wiki com informações & - Wiki com informações & - Wiki com informações \\
sobre projetos e sistemas. & para divulgar e & sobre os projetos de software. \\
- Sites com informações & compartilhar problemas. & - Registro e busca de lições \\
dos projetos de software. & - Portal da qualidade. & aprendidas. \\
- Site com informações & - Sistema de & - Ambiente de integração de \\
sobre o processo de & acompanhamento de & grupos sociais. \\
desenvolvimento de & projetos e histórico de & \\
software. & projetos. & \\
\hline
\end{tabular}

Fonte: dados da pesquisa

A Empresa A considera a intranet como um sistema de GC na parte em que existe o compartilhamento de conhecimento de projetos, no portal da qualidade e no Wiki. Para a Empresa B, a intranet pode ser utilizada como um sistema de GC, dependendo de como a intranet esteja estruturada. Ela pode ser um repositório de conhecimento e artefatos ou um conjunto de sistemas que dá apoio a outras ferramentas mais direcionadas à GC, como o Wiki, o sistema de registro e busca de lições aprendidas de projetos e o ambiente de integração de grupos sociais. A Empresa X considera a intranet uma ferramenta para apoio aos processos de GC, utilizando o $\mathrm{Wiki}_{2}$ os sites com informações de projetos e sistemas e o site que apresenta o processo de desenvolvimento de software. As três empresas concordaram que a intranet pode ser utilizada como uma ferramenta que auxilia o processo de desenvolvimento de software.

Os entrevistados das empresas concordaram que a qualidade da informação da intranet, 
Análise dos atributos para avaliação da qualidade da informação nos ambientes de intranet para apoio à gestão do conhecimento

quando utilizada como um sistema de GC, pode influenciar o processo de desenvolvimento de software. As empresas X e B relacionaram a qualidade da informação com a credibilidade das informações da intranet e a continuidade do uso da intranet. O entrevistado B4 salienta que "se as pessoas têm consciência de que a informação que está publicada na intranet é de qualidade, eles vão utilizar a informação, o que dá credibilidade à informação". Para a Empresa A, se a informação disponibilizada na intranet tiver qualidade, será um insumo importante para a condução do projeto de software.

A análise dos resultados das opiniões dos entrevistados das empresas X, A e B - com relação à aplicabilidade dos atributos da qualidade da informação para avaliar as informações disponibilizadas nas intranets, no apoio ao desenvolvimento de software - levou em consideração o grau de importância atribuído pelos entrevistados aos atributos. No Quadro 6, apresenta-se a comparação dos atributos considerados importante ou muito importante pela maioria dos entrevistados nas três empresas, que são aqueles identificados como aplicáveis para avaliação da qualidade da informação neste contexto.

Quadro 6 - Comparação com relação à aplicabilidade dos atributos

\begin{tabular}{|c|c|l|c|c|c|}
\hline Aspectos & Classificação & Atributos & Empresa X & Empresa A & Empresa B \\
\hline \multirow{4}{*}{ Conteúdo } & Principal & Precisão & Aplicável & Aplicável & Aplicável \\
\cline { 2 - 6 } & Principal & Clareza & Aplicável & Aplicável & Aplicável \\
\cline { 2 - 6 } & Principal & Relevância & Aplicável & Aplicável & Aplicável \\
\cline { 2 - 6 } & Principal & Credibilidade & Aplicável & Aplicável & Aplicável \\
\cline { 2 - 6 } & Secundário & Fonte & Aplicável & Aplicável & Aplicável \\
\cline { 2 - 6 } & Secundário & Segurança & Aplicável & Aplicável & Não aplicável \\
\cline { 2 - 6 } & Principal & Completeza & Aplicável & Não aplicável & Aplicável \\
\cline { 2 - 6 } & Secundário & Detalhe & Não aplicável & Aplicável & Não aplicável \\
\hline \multirow{4}{*}{ Tempo } & Principal & Tempestividade & Não aplicável & Aplicável & Aplicável \\
\cline { 2 - 6 } & Principal & Atualidade & Aplicável & Aplicável & Não aplicável \\
\cline { 2 - 6 } & Secundário & Histórico & Aplicável & Aplicável & Não aplicável \\
\cline { 2 - 6 } & Secundário & Freqüência & Não aplicável & Aplicável & Não aplicável \\
\cline { 2 - 6 } & Secundário & Período & Não aplicável & Aplicável & Não aplicável \\
\hline \multirow{4}{*}{ Forma } & Secundário & Ordem & Aplicável & Aplicável & Aplicável \\
\cline { 2 - 6 } & Secundário & Acessibilidade & Não aplicável & Aplicável & Aplicável \\
\cline { 2 - 6 } & Secundário & Disponibilidade & Não aplicável & Aplicável & Aplicável \\
\cline { 2 - 6 } & Principal & Apresentação & Não aplicável & Aplicável & Não aplicável \\
\cline { 2 - 6 } & Secundário & Facilidade de uso & Não aplicável & Aplicável & Não aplicável \\
\cline { 2 - 6 } & Secundário & Interface & Não aplicável & Aplicável & Não aplicável \\
\hline
\end{tabular}

Fonte: dados da pesquisa

A diferença de percepção dos entrevistados com relação à aplicabilidade dos atributos para avaliação da qualidade da informação nas intranets fica evidente ao compararem-se as três empresas. Na empresa A, os entrevistados consideraram aplicáveis 19 atributos, enquanto que nas outras empresas foram considerados 10 atributos. Uma característica da empresa A, 
Ana Lúcia Batista Trindade, Mírian Oliveira \& Grace Vieira Becker

que pode justificar esta diferença, é o tempo de empresa dos entrevistados, pois somente um deles tem mais de 10 anos na empresa, enquanto os demais não têm mais que um ano e meio de atuação na empresa. Outra característica desta empresa é o foco em clientes externos. Neste sentido, as informações dos requisitos dos projetos de software são obtidas com os clientes externos, e existe a necessidade de compartilhamento das informações com estes clientes durante o processo de desenvolvimento. Na empresa $\mathrm{X}$, os produtos de software são desenvolvidos para clientes internos, ou seja, para áreas de negócio da própria empresa. As informações dos projetos de software são obtidas através dos clientes internos e compartilhadas com as equipes dos projetos e com os clientes internos. Também se destaca a maturidade dos entrevistados da empresa $\mathrm{X}$, que demonstraram vasto conhecimento dos processos da empresa e conhecimento de processos de GC. Durante as entrevistas da empresa $\mathrm{B}$, percebeu-se o foco em processo nesta empresa: existe uma área que define os processos de software e garante que os mesmos sejam seguidos. Na empresa B, a GC está bem difundida e identificou-se a preocupação em disponibilizar ferramentas para que exista o compartilhamento do conhecimento. Estas características das empresas X e B podem justificar a opinião dos entrevistados na identificação de menor quantidade de atributos aplicáveis para avaliar a qualidade da informação da intranet para a GC.

Como resultado da análise, propõe-se considerar como atributos da qualidade da informação para avaliação da qualidade da informação das intranets na gestão de conhecimento, no contexto do processo de desenvolvimento de software: os atributos avaliados como muito importante ou importante pelas três empresas pesquisadas; os atributos considerados principais pelos especialistas que foram considerados aplicáveis por pelo menos duas empresas. Os atributos selecionados são apresentados no Quadro 7, juntamente com o aspecto da informação a que se propõe avaliar.

Quadro 7 - Atributos da Qualidade da Informação resultado da análise das Empresas X, A e B

\begin{tabular}{|l|l|}
\hline \multicolumn{1}{|c|}{ Atributos } & \multicolumn{1}{c|}{ Foco do Atributo } \\
\hline Precisão & Conteúdo com relação à correção da informação. \\
\hline Clareza & Conteúdo com relação ao entendimento da informação. \\
\hline Relevância & Conteúdo com relação à utilização da informação. \\
\hline Credibilidade & Conteúdo com relação à confiança da informação. \\
\hline Fonte & Conteúdo com relação à confiança da informação. \\
\hline Ordem & Apresentação para o entendimento da informação. \\
\hline Completeza & $\begin{array}{l}\text { Conteúdo com relação a prover toda a informação } \\
\text { necessária. }\end{array}$ \\
\hline Atualidade & Tempo com relação à idade da informação. \\
\hline Tempestividade & Tempo adequado para disponibilização da informação. \\
\hline
\end{tabular}


Análise dos atributos para avaliação da qualidade da informação nos ambientes de intranet para apoio à gestão do conhecimento

Os atributos da qualidade da informação sugeridos são aplicáveis para as empresas pesquisadas. É necessário que cada empresa identifique o conjunto de atributos que atenda o seu contexto e seus objetivos.

\section{Análise dos resultados}

A qualidade da informação nos sistemas de gestão do conhecimento pode ser um fator que influencia a utilização da informação. Se a informação disponibilizada nos sistemas de gestão de conhecimento é de baixa qualidade, pode representar uma barreira na transformação do conhecimento individual em conhecimento organizacional. No contexto das empresas de desenvolvimento de software - em que o conhecimento é um recurso crítico que precisa ser gerenciado em todas as etapas do processo - a utilização de sistemas de gestão de conhecimento é um apoio para este processo. Estes sistemas vão permitir que o conhecimento seja armazenado, encontrado e utilizado.

Os autores analisados aplicaram os estudos de qualidade da informação nos sistemas de data warehousing, e-business, bancários, sistemas que utilizam tecnologia web e em sistemas que suportam a memória e o conhecimento organizacional, este último o único voltado à GC. A busca na literatura resultou num conjunto de 40 atributos da qualidade da informação aplicados em estudos anteriores.

Durante as entrevistas com os especialistas e com os entrevistados das empresas pesquisadas, foi possível confirmar a importância da GC para as organizações, pois se trata de uma forma de manter o conhecimento dentro da organização e de disponibilizar o conhecimento das pessoas em benefício da própria organização. A GC é percebida como um meio para melhorar o desempenho das pessoas, trazendo mais produtividade. No entanto, as empresas ainda encontram dificuldades, pois existem aspectos culturais e de infra-estrutura que dificultam fazer com que as pessoas busquem, compartilhem e reutilizem o conhecimento.

A intranet foi percebida pelos entrevistados como uma ferramenta de GC que pode auxiliar neste processo. No entanto, a intranet vem sofrendo uma reformulação nas empresas a fim de que possa ser utilizada na GC. A Empresa X, que vê a intranet como um portal de comunicação dos grupos de indivíduos, a está utilizando para unir grupos através de fóruns, realizar pesquisas e também como um repositório de conhecimento; pode ser, além disto, 
Ana Lúcia Batista Trindade, Mírian Oliveira \& Grace Vieira Becker

considerada um veículo para trabalhar com GC. Na Empresa A, a parte da intranet em que existe o compartilhamento de conhecimento de projetos, as lições aprendidas de projetos, as discussões de problemas e o portal de qualidade, é entendida como um apoio à GC. Na Empresa B, a intranet permanece com a sua característica informativa, agregando outros ambientes para gerir o conhecimento, como a aplicação do Wiki, uma ferramenta para registro e busca de lições aprendidas de projetos, e o ambiente de integração de grupos sociais. As empresas entendem que existe um desafio para que as ferramentas de gestão de conhecimento sejam efetivamente utilizadas, pois as pessoas ainda não se sentem motivadas a participar deste ambiente colaborativo de compartilhamento de conhecimento.

Os autores (MASREK; KARIM; HUSSEIN, 2008; NEWELL; SCARBROUGH; SWAN, 2001; SCOTT, 1998) apontam a intranet com uma tecnologia que pode ser utilizada para proporcionar integração entre as pessoas, ou como uma interface para acesso a outras aplicações - e, desta forma, ser empregada como uma ferramenta para o compartilhamento de conhecimento. Confirma-se este aspecto nas entrevistas dos usuários da intranet; as empresas a estão utilizando como um meio para acessar ambientes em que existe a troca de conhecimento.

Os entrevistados percebem que, durante as etapas do processo de desenvolvimento de software, existem diversas situações em que as informações disponibilizadas no ambiente da intranet servem de base para a tomada de decisão. As principais etapas do processo de desenvolvimento identificadas, nas quais se utilizam informações da intranet, foram as de planejamento e desenvolvimento. No planejamento, informações de lições aprendidas de projetos anteriores contribuem para o planejamento de riscos e estimativas. No desenvolvimento, as informações podem ser utilizadas para definição de tecnologia e resolução de problemas técnicos. Contudo, nota-se que as empresas ainda não estão utilizando de uma maneira efetiva as informações disponibilizadas nas ferramentas da intranet com o propósito de compartilhamento de conhecimento.

Após a revisão na literatura dos conceitos e atributos da qualidade da informação sugeridos pelos autores, iniciou-se a primeira fase da pesquisa, em que foi realizada uma análise dos especialistas na relação de atributos pesquisados. Esta análise resultou na seleção de dois grupos de atributos: os atributos chamados de principais, que são 9 atributos considerados mais relevantes para avaliação da qualidade da informação no contexto pesquisado; e os atributos secundários, os quais são agrupados e resultam em 17 atributos, 
Análise dos atributos para avaliação da qualidade da informação nos ambientes de intranet para apoio à gestão do conhecimento

sofrendo ainda críticas dos especialistas.

$\mathrm{Na}$ segunda fase da pesquisa, procurou-se avaliar, com usuários da intranet que executavam diferentes funções nas empresas de desenvolvimento de software, os atributos identificados pelos especialistas. Os usuários da intranet contribuíram com a pesquisa confirmando os atributos identificados pelos especialistas, bem como acrescentando outros que tinham recebido críticas dos especialistas.

O Quadro 8 apresenta os atributos da qualidade da informação considerados mais relevantes pelos especialistas e aqueles considerados mais importantes pelos usuários de intranet das empresas pesquisadas.

\section{Quadro 8 - Atributos da Qualidade da Informação selecionados pelos Especialistas e Usuários}

\begin{tabular}{|l|c|c|}
\hline \multicolumn{1}{|c|}{ Atributos } & $\begin{array}{c}\text { Resultado dos } \\
\text { Especialistas }\end{array}$ & $\begin{array}{c}\text { Resultado dos } \\
\text { Usuários }\end{array}$ \\
\hline Precisão & $\checkmark$ & $\checkmark$ \\
\hline Clareza & $\checkmark$ & $\checkmark$ \\
\hline Relevância & $\checkmark$ & $\checkmark$ \\
\hline Credibilidade & $\checkmark$ & $\checkmark$ \\
\hline Fonte & & $\checkmark$ \\
\hline Ordem & $\checkmark$ & $\checkmark$ \\
\hline Completeza & $\checkmark$ & $\checkmark$ \\
\hline Atualidade & $\checkmark$ & $\checkmark$ \\
\hline Tempestividade & $\checkmark$ & \\
\hline Apresentação & $\checkmark$ & \\
\hline Concisão & & $\checkmark$ \\
\hline Total de Atributos considerados principais pelos especialistas: 9 \\
\hline \multicolumn{2}{|c|}{ Total de Atributos considerados aplicáveis pelos usuários: 9 } \\
\hline \multicolumn{2}{|c|}{ Fonte: dados da pesquisa }
\end{tabular}

Nota-se a diferença de dois atributos na percepção dos especialistas e dos usuários de intranet. Entende-se que esta diferença na percepção dos dois grupos se deve ao fato de que os especialistas apresentam um enfoque mais técnico e acadêmico, enquanto os usuários basearam as suas opiniões nas suas necessidades vivenciadas no seu dia-a-dia, durante a execução das atividades de desenvolvimento de software.

\section{Conclusões}

Com base nas percepções apontadas pelos especialistas e pelos entrevistados das empresas, a escolha dos atributos da qualidade da informação deve ser relevante ao contexto do ambiente de desenvolvimento de software. A sugestão dos entrevistados é de aplicação de uma avaliação da qualidade da informação através de notas percebidas pelos usuários do 
Ana Lúcia Batista Trindade, Mírian Oliveira \& Grace Vieira Becker

conteúdo das áreas da intranet e uma avaliação através de comentários dos usuários avaliando os atributos da informação escolhidos.

Identificou-se que, para os atributos selecionados, existe um relacionamento, observado pelos comentários dos entrevistados quando avaliavam a importância dos atributos da qualidade da informação. A Figura 1 apresenta o relacionamento entre os atributos, através de um diagrama de relações, em que os retângulos representam os atributos e as setas indicam as influências e dependências dos atributos. Estas relações foram identificadas através da análise de conteúdo das entrevistas realizadas nas empresas, quando os entrevistados espontaneamente indicaram a relação entre os atributos.

\section{Figura 1 - Relacionamento entre os atributos da Qualidade da Informação selecionados}

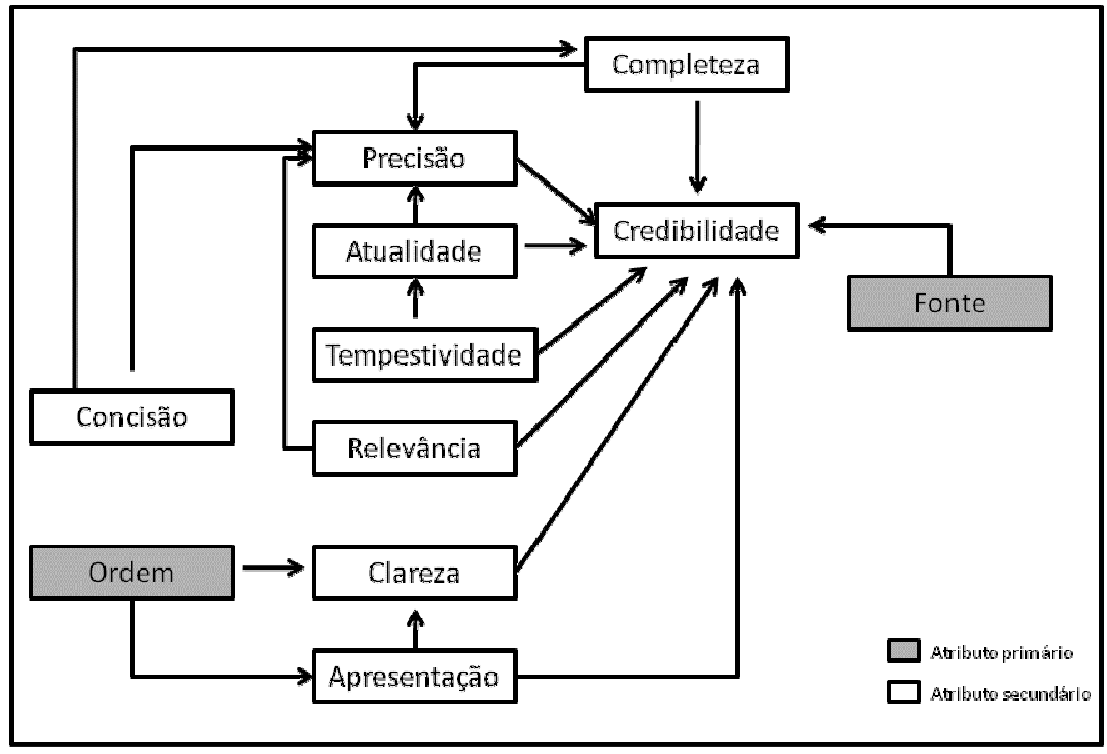

Fonte: dados da pesquisa

Observa-se que, na percepção dos entrevistados, o atributo credibilidade é o resultado da avaliação dos demais atributos. A informação terá credibilidade se quem a produziu for confiável (fonte) e se o usuário entender que a informação possui as características necessárias para que possa ser utilizada (for precisa, atual, completa, relevante, clara, na forma adequada e no tempo certo). A precisão da informação, que representa a informação correta, será influenciada por outros atributos, os quais se complementam de forma que a informação venha a ser percebida como correta (atualidade e completeza). A relevância da informação dentro de um contexto pode ser influenciada pela precisão. Para avaliar a clareza, é necessário avaliar se a informação está sendo apresentada de uma forma que seja de fácil compreensão. Por isto, entende-se que os atributos ordem e apresentação estão relacionados 
Análise dos atributos para avaliação da qualidade da informação nos ambientes de intranet para apoio à gestão do conhecimento

com a clareza. Estes atributos influenciam o entendimento da informação. A concisão da informação influenciará na clareza, precisão e completeza da informação. Uma informação concisa pode perder a precisão e a completude. Os atributos que avaliam o aspecto temporal da informação (tempestividade e atualidade) estão relacionados, pois os usuários mencionaram que, se a informação é disponibilizada no momento certo, a tendência é de que esteja atualizada. A visão do relacionamento existente entre os atributos pode auxiliar na escolha dos atributos da qualidade da informação que serão aplicados no processo de avaliação da qualidade.

Entende-se que, no geral, todos os atributos pesquisados são pertinentes para avaliação da qualidade da informação; no entanto, considera-se como contribuição desta pesquisa a identificação de atributos pertinentes ao ambiente de intranet como apoio à GC no processo de desenvolvimento de software. Os atributos sugeridos resultam da percepção dos entrevistados das empresas pesquisadas e são considerados aplicáveis no ambiente destas empresas. Cabe ressaltar que não existe um padrão de atributos para todas as empresas - cada uma identificará o conjunto de atributos que melhor atende aos seus objetivos, e que este conjunto deve ter entre 5 e 10 atributos.

Como o foco desta pesquisa foi analisar a aplicação dos atributos da qualidade da informação em ambientes de intranet, percebeu-se que a estruturação e utilização das intranets nas empresas não seguem um padrão. $\mathrm{O}$ ambiente de compartilhamento de conhecimento nas intranets tem formatos diferentes nas empresas pesquisadas; as três empresas utilizam a intranet de forma diferenciada. Estas diferenças podem ser consideradas uma limitação da pesquisa, pois a percepção das empresas com relação à relevância dos atributos da qualidade da informação está associada à forma como estas utilizam atualmente a intranet como ferramenta de apoio à GC.

Sugere-se, como continuação deste trabalho, a validação do conjunto de atributos da qualidade da informação obtido como resultado desta pesquisa, através de uma pesquisa quantitativa. Entende-se também importante verificar se o conjunto de atributos sugeridos é aplicável em outro tipo de sistema utilizado como apoio à gestão de conhecimento diferente da intranet. 
Ana Lúcia Batista Trindade, Mírian Oliveira \& Grace Vieira Becker

\section{REFERÊNCIAS}

ALTER, S. Information systems: a management perspective. MA: Addison-Wesley, 1999.

BARDIN, L. Análise de conteúdo. Paris: PUF, 1977.

CONRADIE, J.; KRUGER, P. S. The necessity of information quality for effective business intelligence. South African Journal of Industrial Engineering, v.17, n.1, p. 129-147, 2006.

EDENIUS, M.; BORGERSON, J. To manage knowledge by intranet. Journal of Knowledge Management, v.7, n.5, p. 124-136, 2003.

GIL, A. Como elaborar projetos de pesquisa. São Paulo: Atlas, 1991.

HOPPEN, N.; LAPONTE, L.; MOREAU, E. Avaliação de artigos de pesquisa em sistemas de informação: proposta de um guia. In: Anais do Encontro Nacional do Programas de PósGraduação em Administração, Rio das Pedras. Anais... Rio de Janeiro: Anpad, 1997.

JASIMUDDIN, S. M. Exploring knowledge transfer mechanisms: the case of a UK-based group within a high-tech global corporation. International Journal of Information Management, v.27, n.4, p. 294-300, 2007.

JENNEX, M. E.; OLFMAN, L. Organizational Knowledge effects on productivity, a longitudinal study. In: Proceedings of Annual Hawaii International Conference, Hawaii.

Anais... Hawaii: AHIC, 2002

KAHN, B. K.; STRONG, D. M.; WANG, R. Y. Information quality benchmarks: product and service performance. Communications of the ACM, v.45, n.4, p. 184-192, 2002.

KIM,Y. J.; KISHORE, R.; SANDERS, G. L. From DQ to EQ: understanding data quality in the context of e-business systems. Communications of the ACM, v.48, n.10, p. 75-81, 2005.

LEE, J.-H.; KIM, Y.-G. A stage model of organizational knowledge management: a latent content analysis. Expert Systems with Applications, v.20, n.4, p.299-311, 2001.

LIMA, L. F.; MAÇADA, A. G. Modelo para a qualidade da informação na indústria bancária - caso dos bancos públicos. IN: Anais do Encontro Nacional do Programas de Pós-Graduação em Administração, Rio de Janeiro. Anais... Rio de Janeiro: Anpad, 2007.

MALHOTRA, Naresh K. Pesquisa de Marketing - Uma orientação aplicada. Porto Alegre: Bookman, 2001. 
Análise dos atributos para avaliação da qualidade da informação nos ambientes de intranet para apoio à gestão do conhecimento

MASREK, M.; KARIM, N. S.; RUSSEIN, R. The effect of organizational and individual characteristics on corporate intranet utilization. Information Management and Computer Security, v.16, n.2, p. 89-112, 2008.

NEWELL, S., SCARBROUGH, H., \& SWAN, J. From global knowledge management to internal electronic fences: contradictory outcomes from intranet development. British Journal of Management, v.12, n.2, p. 97-111, 2001.

NONAKA, I. A dynamic theory of organizational knowledge creation. Organization Science, v.5, n.1, p. 14-37, 1994.

O'BRIEN, J. Sistemas de Informação e as Decisões na Era da Internet. São Paulo: Saraiva, 2003.

PIPINO,L.; LEE, Y. W.; WANG, R. Y. Data Quality assessment. Communications of the ACM, v.45, n.4, p. 211-218, 2002.

PRICE, R.; SHANKS, G. A semiotic information quality framework: development and comparative analysis. Journal of Information Technology, v.20, n.2, p. 88-102, 2005.

REDMAN, T. The impact of poor data quality on the typical enterprise. Communications of the ACM, v.41, n.2, p. 79-82, 1998.

RUS, I.; LINDVALL, M. Knowledge management in software engineering. IEEE Software, v.19, n.3, p. 26-38, 2002.

SCOTT, J. E. Organizational knowledge and intranet. Decisions Support Systems, v.23, n.1, p. 3-17, 1998.

SHAH, H.; EARDLEY, A.; WOOD-HARPER, T. Altar in action: knowledge management. European Journal of Information Systems, v.16, n.6, p. 771-779, 2007.

SHANKARANARAYAN, G.; ZIAD, M.; WANG, R. Managing data quality in dynamic decision environments: an information product approach. Journal of Database Management, v.14, n.4, p. 14-32, 2003.

SKOK, W.; KALMANOVITCH, C. Evaluating the role and effectiveness of an intranet in facilitating knowledge management: a case study at Surrey County Council. Information \& Management, v.42, n.5, p. 731-744, 2005.

STENMARK, D. (2002). Information vs. knowledge: the role of intranets in knowledge management. In: Proceedings of Annual Hawaii International Conference, Hawaii. Anais... Hawaii: AHIC, 2002. 
STRONG, D. M.; LEE, Y. W.; WANG, R. Y. Data quality in context. Communications of the ACM, v.40, n.5, p. 103-110, 1997.

TEIXEIRA FILHO, J. Gerenciando conhecimento: como a empresa pode usar a memória organizacional e a inteligência competitiva no desenvolvimento de negócios. Rio de Janeiro: SENAC, 2000.

TOFFLER, A. A terceira onda. Rio de Janeiro: Record, 2000.

WAND, Y., \& WANG, R.Y. Anchoring data quality dimensions in ontological foundations. Communications of the ACM, v.39, n.11, p. 86-95, 1996.

WIXOM, B., \& WATSON, H. An empirical investigation of the factors affecting data warehousing success. MIS Quarterly, v.25, n.1, p. 17-41, 2001.

WIXOM, B.; TODD, P. A theoretical integration of user satisfaction and technology acceptance. Information Systems Research, v.16, n.1, p. 85-102, 2005.

YIN, R. K. Estudo de Caso - Planejamento e Métodos. Porto Alegre: Bookman, 2005. 